\title{
Pott's Puffy tumor and intracranial complication developing secondary to acute frontal sinusitis: A case report
}

\author{
Akut frontal sinüzite bağlı gelişen Pott's Puffy tümör ve intrakraniyal \\ enfeksiyon: Olgu sunumu
}

Tuba BAYINDIR ${ }^{1}$, Çiğdem FIRAT ${ }^{2}$, Ali ÖZERK ${ }^{1}$, Zeynep ÖZDEMIR ${ }^{3}$, Namık ÖZTANIR ${ }^{4}$

ABSTRACT

Pott's puffy tumor is a complication that can be seen after frontal sinusitis and considered as a surgical emergency. Although it is rare, given the potential for significant morbidity, a high index of suspicion for Pott's puffy tumor is required in patients presenting with fluctuant, tender, erythematous swelling of the scalp. High clinical suspicion for the diagnosis of the disease and confirmation of the diagnosis with imaging studies are necessary. In treatment it is important to combine the medical and surgical treatment modalities to avoid intracranial complications. In this case report, a male patient with a Potts puffy tumour developed after frontal sinusitis was presented.

Keywords: Pott's puffy tumor, frontal sinusitis, osteomyelitis, intracranial complication

öz

Pott's puffy tümör frontal sinüzitlerden sonra görülebilen bir cerrahi acili olarak kabul edilebilecek bir komplikasyondur. Ender olmasına rağmen, ciddi morbiditesi olduğu için, skalpte fluktasyon eritematöz şişlikle giden durumlarda Pott's puffy tümörden şiddetle şüphenilmelidir. Bu hastalığın tanısında klinik olarak şüphelenmek ve görüntüleme yöntemleri ile tanıyı doğrulamak gerekir. Tedavide intrakraniyal komplikasyonlardan kaçınmak için cerrahi ve medikal tedavi yöntemlerinin kombine edilmesi önemlidir. Bu olgu sunumuda akut frontal sinüzite bağlı gelişen Potts puffy tümörlü bir erkek hasta sunulmuştur.

Anahtar kelimeler: Pott's Puffy tümör, frontal sinüzit, osteomiyelit, intrakraniyal komplikasyon

bağlı olarak da görülebilir ${ }^{1,2}$.

\section{Giriş}

Ilk olarak 1768 'de Sir Pervical Pott tarafından tanımlanmış olan "Pott's puffy tümör" frontal sinüzit sonrası frontal kemiğin osteomyeliti ile seyreden subperiostal abse olup, antibiyotik tedavilerin düzenli kullanımıyla son yıllarda daha ender görülmeye başlanmıştır. Ancak epidural, subdural ya da frontal lob absesi gibi diğer pürülan intrakraniyal komplikasyonlarla ilişkili olabilir. Genellikle akut ya da kronik frontal sinüzitin komplikasyonu olarak görülmekle birlikte, frontal kemik travması, intranazal kokain kullanımı, fungal enfeksiyon, kranioplasti öyküsü, böcek ısırığı, akupunktur ya da frontal sinüs mukoseline
Tipik klinik bulguları, baş ağrısı, periorbital ödem, pürülan burun akıntısı, ateş ve bulantıdır. Tüm yaş gruplarında görülebilen bu komplikasyon çocuklarda ve adolesanlarda daha sık görülmektedir³.

Epidural abse, menenjit, subdural ampiyem, beyin parankimal absesi, venöz tromboflebit frontal sinüzite bağlı görülebilecek diğer supuratif intrakraniyal komplikasyonlar arasındadır. Komplikasyonlar enfeksiyonun direkt yayılımı veya frontal sinüsün venöz drenajı yoluyla oluşmaktadır ${ }^{1,2,4}$.

Received: 19.01.2016

Accepted: 08.02.2016

${ }^{1}$ Inonu University Faculty of Medicine Department of Otorhinolaryngology

${ }^{2}$ Malatya State Hospital Department of Otorhinolaryngology

${ }^{3}$ Inonu University Faculty of Medicine Department of Radiology

${ }^{4}$ Inonu University Faculty of Medicine Department of Neurosurgery

Yazışma adresi: Tuba Bayındır, Inonu University Faculty of Medicine Department of Otorhinolaryngology, Malatya

e-mail: tuba.bayindir@inonu.edu.tr 
Frontal sinüzite bağlı gelişen intrakraniyal komplikasyonlarda tipik veya tanı koydurucu bir laboratuvar bulgusu olmamakla birlikte, lökositoz, yüksek eritrosit sedimantasyon hızı, CRP yüksekliği görülebilir. Tanı kontrastlı bilgisayarlı tomografi (BT) ile koyulur. Ek intrakraniyal komplikasyon şüphesi varlığında kontrastlı kranial manyetik rezonans görüntüleme (MRG) de yapılmalıdır ${ }^{3,5}$.

Bu komplikasyonda tedavinin temelini geniş spektrumlu intravenöz antibiyotikler ve erken yapılacak cerrahi müdahale oluşturmaktadır.

Bu olgu sunumuda akut frontal sinüzite bağlı gelişen Potts puffy tümörlü ve tedavi altında iken, subdural abse ve serebrite bağlı geçici nörolojik defisit gelişen 17 yaşında adolesan bir erkek hasta sunulmuştur.

\section{OLGU SUNUMU}

On yedi yaşında erkek hasta kliniğimize alında şişlik ve baş ağrısı yakınmaları ile başvurdu. Başvuru sırasında akut rinosinüzit tanısıyla dış merkezde başlanmış olan intravenöz (iV) sefalosporin tedavisinin yedinci gününde idi. Muayenesinde frontal bölgede orta hatta hassasiyet gösteren, üzeri hiperemik şişlik (Figür 1), endoskopik muayenede ise her iki burun pasajında ve nazofarenkste yoğun pürülan sekresyon gözlendi. Laboratuvar tetkiklerinde; WBC:13.5/ $\mathrm{mm}^{3}$, Sedimentasyon:109 mm/saat, CRP:12.7 mg/ dl idi. Aksiyel ve koronal planda çekilen paranazal sinüs bilgisayarlı tomografisinde "frontal ve etmoid sinüzit, sol frontal bölgede $6,5 \times 2 \mathrm{~cm}$ boyutta abse ve frontal sinüste kemik erozyonu" tespit edildi (Figür $2 \mathrm{a}, \mathrm{b})$. Hastaya akut frontal rinosinüzit komplikasyonu tanısıyla yatış verilerek, Sulbaktam-ampisilin

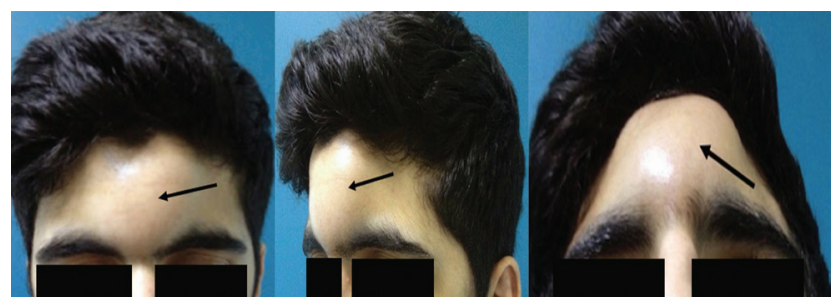

Figür 1. Başvuru sırasında hastanın görüntüsü.

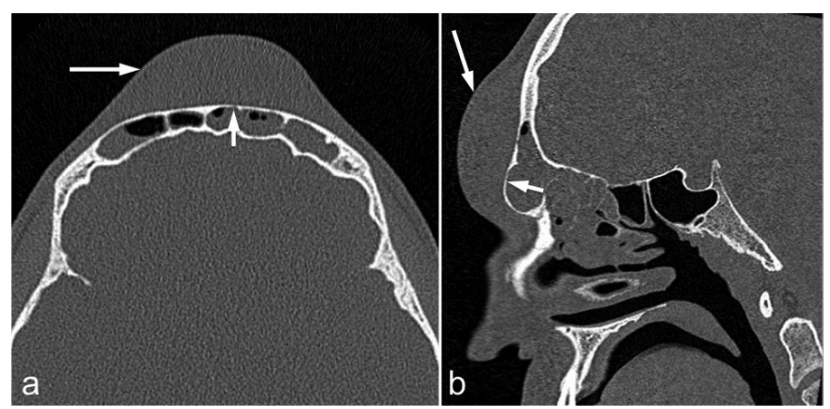

Figür 2a-b. Frontal sinüste Potts Puffy tümörü gösteren aksiyel (a) ve sagital kesitler (uzun oklar). Ayrıca frontal kemikteki kemik erozyunu (kısa oklar).

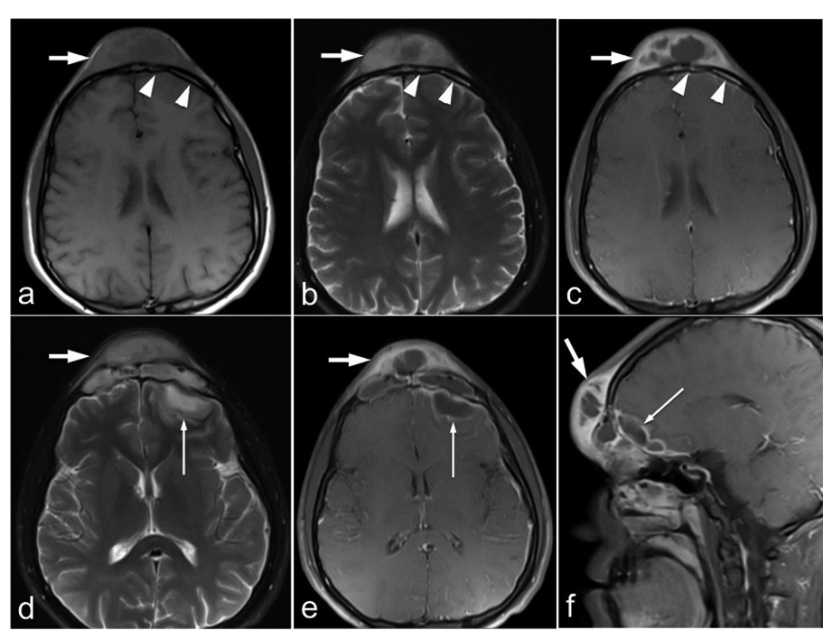

Figür 3a-f. Aksiyel T1a (a) ve T2 (b) ve intravenöz kontrast tutan T1 ağırlıklı (c) MR görüntüleme de kemik iliği ödemi ve osteomiyelit ile uyumlu frontal kemikte kalınlaşma (ok başları), aksiyel T2 ağırıklı (d), aksiyel ve sagital intravenöz kontrast tutan T1 ağırlıklı $(e, f) M R$ görüntülemede çevre beyin parankiminde hafif ödemle birlikte geniş frontal subdural ampiyem (ince uzun oklar). Ayrıca frontal sinüzitle birlikte subperiostal abse (Pott's puffy tumor) (kalın uzun oklar).

4x1,5 g/gün+Metronidazol 3×500 mg/gün intravenöz (iv) yolla başlandı. Çekilen MRG "Frontal bölgede $7,5 \times 2 \times 6 \mathrm{~cm}$ boyutta abse, bağlantı noktasında frontal kemikde defektif görünüm" şeklinde raporlandı. Bunun üzerine hastaya genel anestezi altında (GAA) endoskopik ve eksternal yaklaşımla sol endoskopik frontal sinüs cerrahisi ve frontal sinüs trefinasyonu yapılarak frontal sinüs içerisi tamamen temizlendi ve reses genişletildi. Sinüs içerisinden alınan mikrobiyolojik örneklerde bakteri üremesi olmadı. Yapılan histopatolojik inceleme de "aktif enflamasyon (şiddetli derecede)" olarak raporlandı. Postoperatif parenteral antibiyotik tedavisine de devam edilen hastanın semptomlarında (baş ağrısı ve alında şişlik) belirgin 
düzelme gözlendi, ancak postoperatif dördüncü gününde aniden ajitasyon, konvulsiyon ve şuur bulanıklığı gibi semptomların gelişmesi üzerine hasta Nöroşirurji Anabilim Dalına konsulte edildi. Çekilen diffüzyonlu beyin MRG'de (Figür 3a-f) "sol frontal parankimde $5 \times 3,5 \times 1,5 \mathrm{~cm}$ boyutta çevresel kontrast tutulumu gösteren, durada kalınlaşmaya neden olan veren çevresel ödem alanına sahip abse ile uyumlu lezyon" raporlanması üzerine hasta beyin cerrahisi tarafından GAA yine cerrahiye alındı. İntraoperatif olarak, beyin dokusunda ileri derecede ödem, parankimde yaygın fokal enfeksiyon (serebrit) (Figür 4) saptandı, sol frontal bölgedeki subdural abse drene edildi. Postoperatif dönemde parenteral medikal tedavisi seftriakson 2x2 g/gün (iV)+Metronidazol 4×500 $\mathrm{mg} / g u ̈ n$ (IV) şeklinde yine düzenlendi. Takiplerinde herhangi bir komplikasyon ya da sekel gelişmeyen hastanın medikal tedavisi amoksilin-klavulanik asit $3 \times 1 \mathrm{~g} /$ gün (oral)+Metronidazol $4 \times 500 \mathrm{mg} /$ gün (oral) olarak üç aya tamamlanacak şekilde düzenlendi. Hasta kontrollere gelmek üzere taburcu edildi.

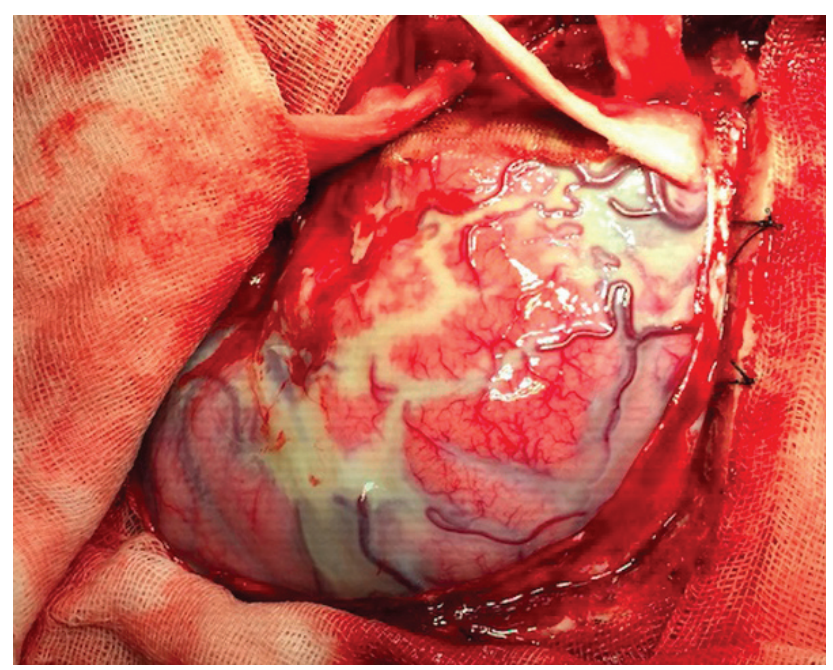

Figür 4. İntraoperatif serebrit görüntüsü.

\section{TARTIŞMA}

Acil cerrahi gerektiren bir komplikasyon olan Pott's puffy tümör genellikle iyi tedavi edilmemiş frontal sinüzitin frontal sinüs ön duvarında osteomyelit ve subperiostal abse oluşumu ile seyreden bir formudur. Frontal sinüs ön duvarı, arka duvarından daha ince yapıda olduğu için abse formasyonuna daha yatkındır ${ }^{6}$.
Tipik klinik bulguları baş ağrısı, alın ya da periorbital şişlik, pürülan burun akıntısı, ateş ve kusmadır ${ }^{5}$. Intrakraniyal abse formasyonunda ise en sık semptom baş ağrısıdır. İntrakraniyal basınç artışıyla bağlantılı olarak görülebilen bulantı-kusma, letarji gibi bulgular ve fokal nörolojik bulgular da sıklıkla baş ağrısına eşlik eden semptomlardır 6 . Olgumuzda, başvuru sırasında Pott's puffy tümörün tipik klinik bulguları olan baş ağrısı ve skalpte fluktasyon veren şişlik olmakla birlikte, dış merkezde başlanmış olan parenteral antibiyotik tedavisinin etkisiyle ateş bulunmamaktaydı. Hastada intrakraniyal komplikasyona ait semptomlar ise ilerleyen günlerde ortaya çıkmıştır.

Ender görülen bir komplikasyon olmakla birlikte, ciddi morbiditesi olduğu için skalpte fluktasyon/eritematöz şişlikle seyreden durumlarda Pott's puffy tümörden şiddetle şüphe edilmelidir. Laboratuvarda spesifik bir bulgusu olmamakla birlikte, eritrosit sedimantasyon hızında artış ve lökositoz görülebilir. Tanı kontrastlı bilgisayarlı tomografi ile koyulur ${ }^{1,7}$. Hastamızda Potts puffy tümör tanısı BT ile koyulurken, santral sinir sistemi enfeksiyonu ve abse tanısı kontrastlı MRG ile koyulmuştur.

Parenteral geniş spektrumlu antibiyotik tedavisi ve eşzamanlı cerrahi müdahale bu komplikasyonun tedavisinde temel yaklaşımdır. Cerrahi tedavide hastalığın şiddetine ve cerrahın tercihine göre frontal sinüs trefinasyonu, kraniotomi, frontal sinüs obliterasyonu ya da frontal sinüs endoskopik sinüzotomisine kadar farklı teknikler tek başına veya kombine olarak kullanılabilir ${ }^{3,7}$.

Tedavi, absenin drenajı, nekrotik dokunun eksizyonu ve patojene bağlı olarak parenteral antibiyotik kullanımından oluşur. Endoskopik cerrahide frontal sinüsün tamamı görülmeli ve patolojik mukozanın tamamı temizlenmelidir. Frontal sinüs obliterasyonu önerilir. Obliterasyon materyalleri hidroksiapatit cement gibi sentetik veya kemik, yağ veya kıkırdak gibi doğal yapılardan oluşabilir. Hidroksiapatit cement frontal sinüs obliterasyonu ve frontal sinüs defektlerinin rekonstriksiyonu için güvenli ve etkilidir. Bu teknik minimal morbiditeye sahiptir ve tam bir osteointegrasyon 
sağlayabilir. Nazal vazokonstriktörler ve mukolitikler tedavide önemlidir. Pott's puffy tümör potansiyel fatal intrakraniyal yayılım ile (ekstradural veya subdural ampiyem) serebral abse ve/veya serebral ven trombozu gibi durumlarla daha komplike olabilir. Pott's puffy tümörde intrakraniyal komplikasyonlar \%60-85 oranında görülür. Ayrıcı tanıda deri yumuşak doku enfeksiyonları, hematom, derinin malign ve benign tümörleri yer alır ${ }^{8,9}$.

Akut/kronik frontal sinüzite bağlı gelişebilen Pott's Puffy tümörün nadir görülen bir komplikasyon olması tanıda gecikmeye yol açabilir. Erken tanı bu hastalarda gelişebilecek fatal komplikasyonları önlemek için önemlidir. Bu hastalıkta tanı koyabilmek için öncelikle klinik olarak şüphelenmek önemlidir. Kesin tanı klinik bulgular ve görüntüleme yöntemleri ile koyulurken, uygun tedavinin erken dönemde başlanması ciddi komplikasyonlardan kaçınmak için şarttır ${ }^{3,8,9}$.

\section{SONUÇ}

Çocuk ve adölesanlarda daha sık görülen akut/kronik frontal sinüzitin bir komplikasyonu olan Pott's puffy tümörde en sık bulgular; baş ağrısı, periorbital ödem, bulantı ve alın bölgesinde şişliktir. Subdural abse ve beyin absesi gibi intrakraniyal komplikasyonlar için risk faktörü olan bu tümörde, cerrahi ve medikal tedavi kombine edilmelidir. Uzun dönemde nörolojik komplikasyonlardan kaçınmak için erken dönemde uygun antibiyotik tedavisinin başlanması özellikle önemlidir. Nüksün erken tanı ve tedavisi için ise yakın klinik ve radyolojik takip gerekmektedir.

\section{KAYNAKLAR}

1. Suwan TP, Mogal S, Chaudhary S. Pott's Puffy Tumor: An Uncommon Clinical Entity. Case Reports in Pediatr 2012;2012:1-4 http://dx.doi.org/10.1155/2012/386104

2. Feder HM Jr, Cates KL, Cementina AM. Pott puffy tumor: a serious occult infection. Pediatrics 1987;79:625-629.

3. Parida PK, Surianarayanan G, Ganeshan S, Saxena SK. Pott's puffy tumor in pediatric age group: a retrospective study. Int J Pediatr Otorhinolaryngol 2012;76:1274-1277. http://dx.doi.org/10.1016/j.ijporl.2012.05.018

4. Raja V, Low C, Sastry A, Moriarty B. Pott's puffy tumor following an insect bite. J Postgrad Med 2007;53:114-116. http://dx.doi.org/10.4103/0022-3859.32212

5. Haider HR, Mayatepek E, Schaper J, Vogel M.Pott's puffy tumor: a forgotten differential diagnosis of frontal swelling of the forehead. J Pediatr Surg 2012;47:1919-1921. http://dx.doi.org/10.1016/j.jpedsurg.2012.06.031

6. Emejulu JKC, Ekweogwu OC. Complicated Pott's Puffy Tumour Involving both Frontal and Parietal Bones: A Case Report. $J$ Infect Dis Ther 2014;2:2-5.

http://dx.doi.org/10.4172/2332-0877.1000166

7. Sullivan $C D$, Poetker DM. Anterior table remodeling after treatment for Pott's puffy tumor. Am J Otolaryngol 2013;34:265-267. http://dx.doi.org/10.1016/j.amjoto.2012.12.018

8. Kelgaonkar YU, Bangad S, Somani SS, et al. Pott's Puffy Tumour: A Rare Complicatıon Of Pansinusitis. International Journal of Basic and Applied Medical Sciences 2012;2:48-50.

9. Avcu G, Belet N, Kurnaz SC, et al. Pott's puffy tumor in a 12year-old boy. Pediatr Int 2015;57:163-165. http://dx.doi.org/10.1111/ped.12440 